\title{
Cirrus, contrails, and ice supersaturated regions in high pressure systems at northern mid latitudes
}

\author{
F. Immler ${ }^{1,3}$, R. Treffeisen ${ }^{2}$, D. Engelbart ${ }^{3}$, K. Krüger ${ }^{4}$, and O. Schrems ${ }^{1}$ \\ ${ }^{1}$ Alfred Wegener Institute for Polar and Marine Research, Bremerhaven, Germany \\ ${ }^{2}$ Alfred Wegener Institute for Polar and Marine Research, Potsdam, Germany \\ ${ }^{3}$ German Meteorological Service (DWD), Richard Aßmann Observatory, Lindenberg, Germany \\ ${ }^{4}$ IFM-GEOMAR, Kiel, Germany
}

Received: 23 August 2007 - Published in Atmos. Chem. Phys. Discuss.: 7 September 2007

Revised: 3 January 2008 - Accepted: 27 February 2008 - Published: 20 March 2008

\begin{abstract}
During the European heat wave summer 2003 with predominant high pressure conditions we performed a detailed study of upper tropospheric humidity and ice particles which yielded striking results concerning the occurrence of ice supersaturated regions (ISSR), cirrus, and contrails. Our study is based on lidar observations and meteorological data obtained at Lindenberg/Germany $\left(52.2^{\circ} \mathrm{N}, 14.1^{\circ} \mathrm{E}\right)$ as well as the analysis of the European centre for medium range weather forecast (ECMWF). Cirrus clouds were detected in $55 \%$ of the lidar profiles and a large fraction of them were subvisible (optical depth $<0.03$ ). Thin ice clouds were particularly ubiquitous in high pressure systems. The radiosonde data showed that the upper troposphere was very often supersaturated with respect to ice. Relating the radiosonde profiles to concurrent lidar observations reveals that the ISSRs almost always contained ice particles. Persistent contrails observed with a camera were frequently embedded in these thin or subvisible cirrus clouds. The ECMWF cloud parametrisation reproduces the observed cirrus clouds consistently and a close correlation between the ice water path in the model and the measured optical depth of cirrus is demonstrated.
\end{abstract}

\section{Introduction}

In his comprehensive work Liou (1986) noted "that cirrus clouds are one of the most important, yet least understood atmospheric elements in our weather and climate systems". Extensive research efforts have been made to overcome this problem. However, as the recent report of the International Panel for Climate Change (IPCC, Solomon et al. (2007))

Correspondence to: F. Immler (franz.immler@dwd.de) demonstrates, Liou's statement is still valid today . The zonally averaged ice water contents (IWC) of the different climate models that are used for the IPCC report (AR4) differ by up to a factor of 10 (Soden, private communication). One reason for this poor performance is that the formation of ice is a very complex process which can occur on different pathways and are parametrised in the model in a rather simplified way. Moreover, measurements of particles and water vapour in the upper troposphere are difficult to conduct and sparse. In particular, there are a number of issues with different types of sensors for water vapour in this altitude region (Kley et al., 2000).

Ström et al. (2003) found from in situ measurements "that the (interstitial) aerosol and cirrus clouds form a continuous system". Depending on where the threshold for particle size or number density is set, a different cloud presence fraction is obtained. This implies that it depends on the instrument used and its detection limits whether a sampled air parcel is considered cloudy or cloud free, which explains the large discrepancy between observations of the cirrus coverage with different sensors (Dessler et al., 2006, e.g.). A clear definition of what should be classified a cirrus cloud is missing to date. A lidar is a very sensitive device for detecting layers of ice particle in the atmosphere and is capable of detecting clouds with optical depths (OD) as low as $10^{-4}$, which occur quite frequently in the tropics, but also at mid-latitudes. This collides with our current understanding of ice formation in the atmosphere since thin ice clouds should either evaporate in a subsaturated environment or grow quickly to thicker clouds in a supersaturated environment (Kärcher, 2002). Optically thin ice clouds with $\mathrm{OD}<0.03$ are often termed subvisible or subvisual cirrus (Sassen et al., 1989). This classification may be meaningful for practical purposes, but there is no indication for any difference in composition, size, or habit between visible and subvisible ice clouds.

Published by Copernicus Publications on behalf of the European Geosciences Union. 
There is a large number of observation indicating that a significant fraction of the upper troposphere is supersaturated with respect to ice (Gierens et al., 1999; Jensen et al., 2001; Spichtinger et al., 2003). Due to the problems mentioned above it remains unclear whether these regions in general contain ice particles or not. Frequently, relative humidities above ice $\left(\mathrm{RH}_{\mathrm{I}}\right)$ of $130 \%$ and higher are observed suggesting that high supersaturations are required in order to nucleate ice. This is contrasted by recent studies which showed that, to a large fraction, ice nucleates on aerosol particles that do not require high supersaturation like dust, sea salt, and solid ammonium nitrate (Cziczo et al., 2004; Abbatt et al., 2006).

It is reasonable to assume that ice formation in the upper troposphere occurs on different pathways depending on aerosol, humidity and dynamics. In order to improve our understanding of ice formation numerous observations at different locations, different instrumentation, and different weather patterns are required. A lot of attention has been paid to the investigation of ice particles in the outflow of deep convection (Heymsfield et al., 2004), in orographic waves (Heymsfield et al., 1998; Toon and Miake-Lye, 1998; Gayet et al., 2006), synoptically forced cirrus along a warm conveyor belt (Heymsfield et al., 1998) and cirrus associated with jet streams (Gayet et al., 2004). However, little attention has been given to thin cirrostratus that form in high pressure systems.

General circulation models like the ECMWF integrated forcast system (IFS) still have problems with correctly representing clouds, in particular cirrus. Palm et al. (2006) found a good agreement of the ECMWF $6 \mathrm{~h}$ and $48 \mathrm{~h}$ forecast and cloud observations in 2003 with a satellite based lidar (GLAS) for low clouds but less good agreement for high clouds. The model overestimated the high cloud fraction. Using again ECMWF forecast data for $6 \mathrm{~h}$ and $48 \mathrm{~h}$ Miller et al. (1999) sees qualitatively good agreement with observations obtained by the Lidar in Space Technology Experiment (LITE) in a preliminary assessment based on data from 1994. Hogan et al. (2001) used lidar and radar for a comparison and found again a good agreement for low and middle clouds but poor agreement for high clouds which was mainly attributed to the failure of the instruments to detect thin (subvisible) clouds. Li et al. (2005) compared opECMWF analysis with MLS observations of IWC and found discrepancies by factors of 2-4.

In summary, the capabilities of the ECMWF's cloud prognostic scheme seem to be good for the prediction of low and mid-level clouds. However, there are still open questions regarding cirrus. These issues are related to both, a lack of reliable observations and the shortcomings of the forecast model to simulate ice clouds, while it is unclear to date which one is the more important problem.

Another important issue is the formation of ice clouds from aircraft exhaust and its climate impact. Commercial airplanes frequently pass near Lindenberg on their typical cruising altitudes of 10-12 km. Aircraft induced lineshaped clouds ("contrails") and spreaded cirrus ("contrail cirrus") are believed to warm the atmosphere by absorbing long-wave radiation (Meerkötter et al., 1999). However, since the microphysical properties of contrails and their impact on cirrus clouds are not known very well, the overall impact of ice formed by aircraft exhaust is still highly uncertain (Penner et al., 1999).

In order to study cirrus, contrail, and upper tropospheric water vapour we have performed a measurement campaign at the Richard-Aßmann Observatory in Lindenberg, Germany $\left(52.2^{\circ} \mathrm{N}, 14.1^{\circ} \mathrm{E}\right)$ with a Mobile Aerosol backscatter and Raman Lidar (MARL) from May to October 2003. Water vapour was measured by radiosondes (Vaisala RS-80) which were launched 4 times a day in the frame of the German Meteorological Service ("Deutscher Wetterdienst", DWD) routine observation program. The humidity data of the radisondes were corrected using an algorithm suggested by Miloshevich et al. (2001) which provides an accuracy of about $5 \%$ in the upper troposphere at high humidities. We investigated the frequency of ISSRs in the upper troposphere and their relation to the occurrence of thin and subvisible cirrus clouds and contrails and compare these observations to model data from the ECMWF.

\section{Method}

\subsection{The Mobile Aerosol Raman Lidar (MARL)}

The MARL detects elastic and inelastic backscatter from a laser beam that is emitted vertically into the atmosphere. A $\mathrm{Nd}$ :YAG laser with an output power of $350 \mathrm{~mJ}$ at $532 \mathrm{~nm}$ and $355 \mathrm{~nm}$ and $30 \mathrm{~Hz}$ repetition rate creates short laser pulses $(\Delta t=7 \mathrm{~ns})$ which are expanded to a beam of $10 \mathrm{~cm}$ diameter and emitted with a divergence of less then $0.2 \mathrm{mrad}$ and a zenith angle of $6 \mathrm{mrad}\left(=0.34^{\circ}\right)$. The lidar signals are detected by means of a $1.1 \mathrm{~m}$ diameter quasi-Cassegrain telescope with a field-of-view of $0.4 \mathrm{mrad}$ and a 10 -channel detection system that uses analogue and single photon counting data acquisition simultaneously (Schäfer et al., 1997). The backscatter profiles are measured at $532 \mathrm{~nm}$ and $355 \mathrm{~nm}$ separated by polarisation. Raman signals of nitrogen and water vapour are excited at $355 \mathrm{~nm}$ and detected at $387 \mathrm{~nm}$ and $407 \mathrm{~nm}$, respectively. The nitrogen Raman signal excited at $532 \mathrm{~nm}$ is detected at $607 \mathrm{~nm}$. The temporal and vertical resolutions are $140 \mathrm{~s}$ and $7.5 \mathrm{~m}$, respectively.

The Raman signals are measured in single photon counting mode (PC) while the elastic backscatter signals (parallel and perpendicular polarisation) are measured simultaneously with PC- mode and by analogue photo current measurements with a 12 bit A/D converter. This detection system was provided by licel GbR, Berlin. The analogue and the PC signals are merged at an altitude where both are linear, typically at $8 \mathrm{~km}$ altitude. Based on a conversion factor determined at that height, the analogue signal is used where the PC signal 
exceeds a counting frequency of $10 \mathrm{MHz}$. At those count rates the PC signal becomes non-linear due to the effect of coincident photons. Merging both signals thus provides a large range of linearity which is particularly important for cirrus measurements: the strong backscatter provided by the ice crystals easily drives the PC signals to saturation while at the edges of the cloud the backscatter signal goes down to the value of molecular scattering. Four orders of magnitude or more in the lidar return signal power may be covered by a single cloud event, in particular in the cross polarised channels.

Cirrus clouds, from the lidar perspective, are layers of particles above $6 \mathrm{~km}$ altitude with a well defined upper and lower boundary and a large vertical and temporal variability, that depolarise light and have a close to zero colour index. The latter is the backscatter related Ångström coefficient and expresses the wavelength dependence of the backscatter coefficient. White clouds (colour index $=0$ ) scatter equally efficient at all visible or near visible wavelengths.

Clouds that do not cope with this definition were excluded from this study. Ice clouds are detected as increased backscatter in the $532 \mathrm{~nm}$ cross polarised channel. As demonstrated by Immler et al. (2007) the detection limit of this system concerning ice clouds is extremely low and clouds with an optical depth of less than $10^{-4}$ can be easily observed. The optical depth (OD) of a cloud is measured either directly by virtue of the nitrogen Raman scattering (Ansmann et al., 1992) or by a method known as the shadow-method: In order to obtain the optical depths the signal loss above the cloud is derived from a comparison of the logarithm of the measured signal $\ln P(h)$ with an synthesised cloud free profile. The loss of signal which is due to the clouds extinction can thus be determined.

Typically, the uncertainty of the direct measurement of the optical depth is about 0.05 for both Raman and shadow method. The extinction-to-backscatter ratio $S$, which is also termed lidar ratio, can be calculated as the ratio of optical depth by the integrated backscatter by assuming that it is constant throughout one cloud layer. On average, we measured a lidar ratio $S$ of 16 for mid-latitude cirrus clouds with a standard deviation of 9 . This value can be used to derive the optical depth of optically thin clouds $(\mathrm{OD}<0.05)$ which can not be directly measured with the lidar. By multiplying the observed particle backscatter coefficient with a lidar ratio of 16 and integrating over the altitude range of the cloud we can derive a reasonable estimate for OD even for extremely thin clouds. The error of this method is mainly caused by the uncertainty in S which is about $60 \%$.

In order to determine cloud types a video camera was installed near the receiving telescope. During day time, a picture of the sky above the lidar system was taken and stored each time the lidar completed a measurement cycle. The camera pictures were used for cloud classification which was performed by visual inspection. Of particular interest was the question whether observed ice particles were related to con- densation trails (contrails) from airplanes. These can be easily identified by their line shape. We categorised the observed clouds into Cirrostratus (Cs), Cirrus (Ci), contrails (Co), and subvisible Cirrosstratus (sCs). The latter was labelled to an observation when the lidar data indicated the presence of ice particles in the upper troposphere, while there was no indication of the presence of clouds found on the camera images. Contrails are further divided into lineshaped contrails (lCo), spreaded contrail ( $\mathrm{sCo}$ ) and contrails embedded in preexisting Cirrostratus (eCo).

\subsection{Radiosonde data}

The DWD launched four radiosondes (Type Vaisala RS-80) per day. We used the temperature profiles measured by the radiosondes for the determination of the thermal tropopause and the cloud temperature. The humidity profiles of the RS80 sondes are known to have a significant dry bias in the upper troposphere which can be corrected (Miloshevich et al., 2001). Based on a comparison with the NOAA frostpoint hygrometer, the accuracy of the corrected RS- 80 humidity data was shown to be about $5 \%$ in the upper troposphere at high humidities (Miloshevich et al., 2006). A comparison of the corrected RS-80 with the improved RS-92 version also showed very good results (Treffeisen et al., 2007).

For the determination of the relative humidity inside cirrus clouds we selected those cases were coincident lidar measurements were available. Coincident here means that the radiosondes, which were launched just a few 100 meters away from the lidar, flew in the upper troposphere during the time period of the lidar measurements. Since for this anaylsis we are using $1 \mathrm{~h}$ avarages of lidar data, it is garanteed or at least very likely that the radiosonde flew within the temporal and horizontal frame of the lidar observation. For a direct comparison of cloud occurrences and relative humidities, the high resolution radiosonde data was interpolated on the altitude grid of the lidar data $(7.5 \mathrm{~m})$. The relative humidity with respect to ice $\left(\mathrm{RH}_{\mathrm{I}}\right)$ is calculated from the relative humidity with respect to water, which is the standard output from radiosondes, using Sonntags formula (Sonntag, 1994).

\subsection{ECMWF data}

In order to interpret our data we use the operational analysis of the integrated forecast system (IFS) of the ECMWF which was made available by AWI Potsdam. The IFS uses the prognostic cloud scheme described by Tiedtke (1993). This scheme was implemented in 1995 and has undergone several revisions since. Version CY25R1 of the IFS was operational in 2003 and is described in the documentation at the ECMWF website (http://www.ecmwf.int/research/ifsdocs/). Of particular interest for this study is the scheme for the formation of stratiform clouds, according to which new clouds form in a grid cell when the relative humidity exceeds a critical value $\mathrm{RH}_{\text {crit }}$ which is $80 \%$ in the mid troposphere and 


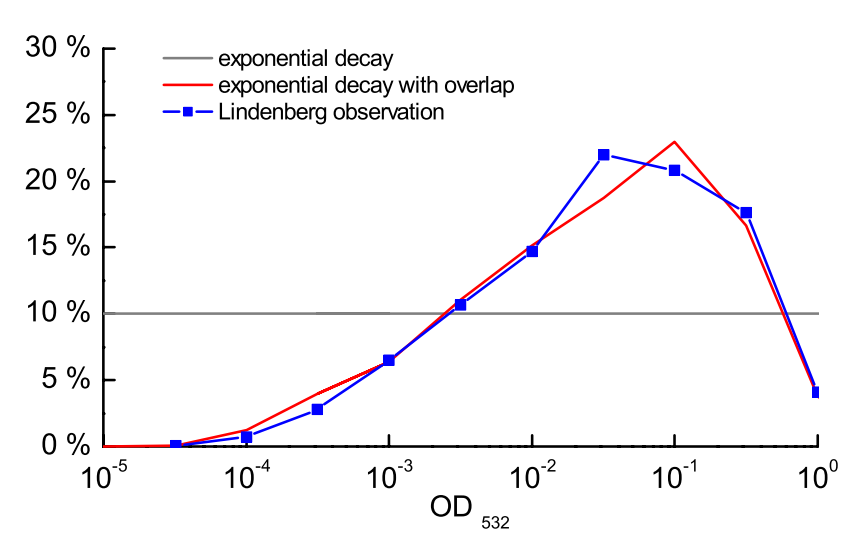

Fig. 1. Frequency of occurrence of optical depths measured with the MARL lidar in Lindenberg from May 2003 to October 2003 (blue line). The red and grey lines show simulated curves based on an exponential decay of clouds with time allowing and not allowing for temporal overlap of clouds, respectively.

approaches $100 \%$ at the tropopause. The relative humidity in operational ECMWF analysis (opECMWF) is defined with respect to the saturation vapour pressure $e_{\text {Sat }}$ of water when the temperature $\mathrm{T}$ is above zero. At lower temperatures $\mathrm{RH}$ is defined with respect to ice when $T<-23^{\circ} \mathrm{C}$, while and an intermediate value of $e_{\text {Sat }}$ is used for the definition of $\mathrm{RH}$ for $0^{\circ}>T>-23^{\circ} \mathrm{C}$. There are no further differences made between the formation of ice and water clouds. Upper tropospheric humidity as well as observations of thin or subvisible cirrus clouds are not assimilated in the operational analysis. Therefore, a comparison of opECMWF data with observations can be considered as a validation of the prognostic clouds scheme.

\section{Results}

From April 2003 to October 2003 the MARL was operated at Lindenberg $\left(52.2^{\circ} \mathrm{N}, 14.1^{\circ} \mathrm{E}\right)$. An intensive observation periods (IOP) was carried out in August and September 2003 where the lidar and the camera were fully operational and extended coherent data were obtained since the system was running in automatic mode. The system operated day and night. It is the cloud coverage that defined its operation status: opaque clouds caused the system to shut down and it restarted automatically when these clouds have disappeared. The data presented below therefore refer to periods without low and mid-level clouds, which are generally opaque. In the following, we will refer to such conditions as "clear", regardless of the occurrence of cirrus. Overall almost $400 \mathrm{~h}$ of lidar observations were carried out during this IOP on 40 days. The cirrus coverage determined on these days is shown in Fig. 2.

\subsection{Cirrus occurrence and live cycle}

During $55 \%$ of the clear periods cirrus clouds were detected by the lidar. These cirrus clouds are generally thin or subvisible. The propability of encountering a cirrus with an optical depth between OD and OD $+d \mathrm{OD}$ decreases rapidly with OD. The change of the propability is more gradual when considering the logarithm of OD. In other words, it is about as likely to detect a cirrus with an optical depth between OD and $f \mathrm{OD}$, with $\mathrm{f}$ being some factor $>1$, for any value of OD within the detection limit of the lidar. The observed probability density function (PDF) of $\log (\mathrm{OD})$ is plotted in Fig. 1. This distribution, in particular its long tail towards thin clouds, seems to be a general feature in the mid-latitudes since similar results were obtained form climatological studies (Goldfarb et al., 2001; Sassen and Campbell, 2001). This observations suggests that some simple, universal mechanism is responsible for this behaviour. The fact that the probability of the occurrence of cirrus is a more even function of the logarithm of the optical depths (OD) rather than of OD itself suggests that cirrus decay according to an exponential law:

$\mathrm{OD}(t)=\mathrm{OD}_{0}: e^{-t / \tau}$

where $\mathrm{OD}_{0}$ is the initial optical depth and $\tau$ the livetime of a cirrus. The PDF of the OD in Fig. 1 can be simulated by assuming an exponential decay given by Eq. (1) of spontaneously occurring cirrus with random optical depth between 0 and 1 in a simple, single-layer box-model. When the total optical depth of the clouds in the box is sampled frequently at random times, the PDF of the $\log [\mathrm{OD}(t)]$ is even when clouds occur so rarely that it is very unlikely to observe two clouds at a time (grey line). A cloud was considered as dissipated when its optical depth has dropped below the detection limit which was set to $10^{-5}$. If the frequency of cloud occurrence is increased in the model and there is some chance for a temporal overlap, it is more likely to observe thicker clouds, since they will dominate the measurement. The PDF will then slightly increase with $\log (\mathrm{OD})$ (red line in Fig. 1).

In summary, the shape of the PDF of the optical depth of stratiform cirrus suggests that their live cycle is dominated by an exponential decay. An exponential decrease of OD of a cloud by time is expected if the decay is due to sedimentation of particles with different sizes and fall speeds (Spichtinger et al., 2006). Unfortunately, the life time $\tau$ of cirrus clouds can not be inferred from the lidar observation. However, the fact that the distribution in Fig. 1 does not change when the integration time is changed from minutes to hours suggests that $\tau$ is at least of the order of hours.

\subsection{Cirrus and synoptic pattern}

The summer 2003 was characterised by persistent high pressure systems residing over central Europe which were occasionally perturbed by lows that passed northly from west 


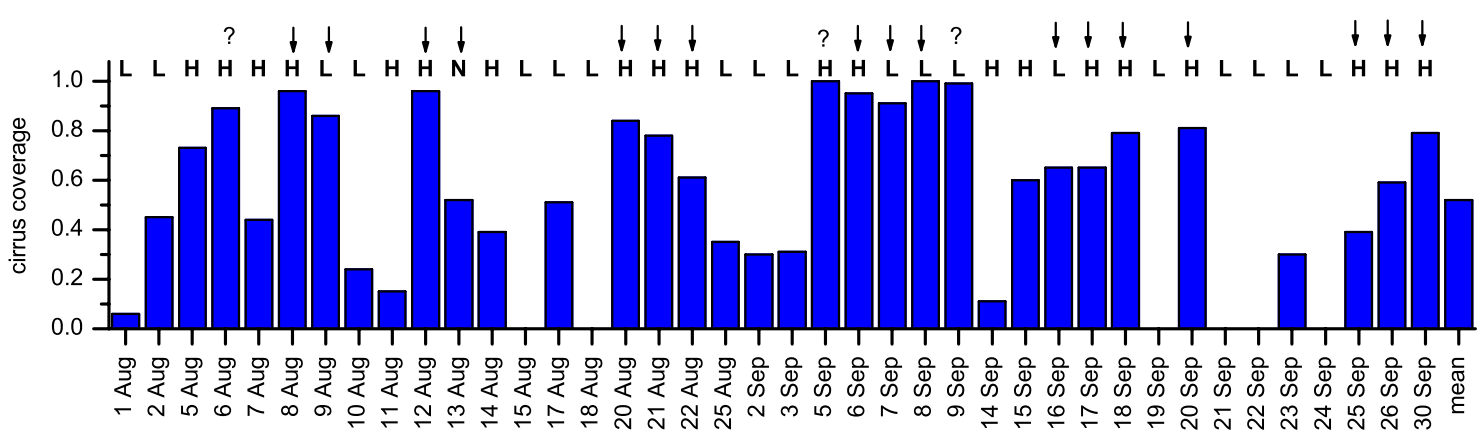

Fig. 2. Cirrus cloud coverage per day for all available measurements in August and September 2003 at Lindenberg. The days with a cyclonic wind field at the ground level are marked with an L, those with an anticyclonic wind field with an H. The arrows on top mark those days, where persistent contrails were observed with the sky camera. The "?" marks the days were the camera was not operational.

to east. These troughs were often accompanied by thunderstorms. Figure 2 shows the cirrus coverage calculated for each day where lidar measurements were performed in $\mathrm{Au}$ gust and September 2003. According to weather charts from 00:00 UTC provided by the DWD, the bars are labelled with an " $\mathrm{H}$ " when the ground level wind field in the region of Lindenberg was anticyclonic (isobars curve towards the right hand side, looking in the direction of the flow). In such a wind pattern the characteristics of a high pressure system are dominant while cyclonic wind fields are related to lows. The days with a cyclonic wind field are marked with "L". Intriguingly, the cloudiness was particularly high in the high pressure systems, while the sky was often free of cirrus under cyclonic conditions.

On days with anticyclonic characteristics, i.e. all day marked with an "H" in Fig. 2, the cirrus coverage was on average $67 \%$ while it was only $37 \%$ on clear days with cyclonic characteristics. On periods dominated by a low pressure system the cirrus coverage can be very high which is usually related to the warm conveyor belt (e.g. 08.09.2003) or very low which is related to the period after the passage of the cold front (e.g. 24.09.2003). High pressure systems are mostly related with high cirrus coverage except for some occasions where the high pressure was still in an early stage (e.g. 11.08.2003 or 14.09.2003).

\subsection{Water vapour and cirrus}

About $60 \%$ of all radiosonde profiles measured in August and September 2003 showed supersaturation in the upper troposphere $(8-13 \mathrm{~km})$. Spichtinger et al. (2003) carried out a study of upper tropospheric water vapour based on radiosonde data from Lindenberg from 2000 and 2001 which were corrected by the DWD algorithm (Leiterer et al., 1997). They found a much smaller value of $28 \%$. The correction algoritm we were using generally yields higher humidities in the upper troposphere than the algorithm used by Spichtinger et al. (2003). This is one reason for this discrepancy in the frequency of ISSRs, because our correction algorithm quite often yielded supersaturation with respect to ice in the UT while this was not obtained when no or the Leiterer algorithm was used. Further more, we were investigating a special time period which could show quite some differences from the climatological mean.

The following analysis is based on $1 \mathrm{~h}$-integrated lidar data and radiosonde profiles that were measured at about the same time ( $\pm 30 \mathrm{~min}$ ). If we consider only those profiles where simultaneous lidar and radiosonde observations exist, the analysis will be biased towards cloud free, i.e. drier, conditions in the lower and middle troposphere. Surprisingly, the percentage of ISSRs occurrence in those profiles rises to $68 \%$. The reason for this is that good lidar observation conditions are more frequent during high pressure weather systems. In anticyclones the tropopause is higher and colder than in cyclones and because of the lower temperatures the relative humidity in the uppermost troposphere is high and often above ice saturation.

Based on the concurrent lidar and radiosonde observations it is possible to study the relation between cirrus formation and ice super saturation in those regions and we found that generally thin cirrus stratus is present where $\mathrm{RH}_{\mathrm{I}}$ is larger than $100 \%$. In about $90 \%$ of all cases where ISSRs were present between 8 and $13 \mathrm{~km}$ altitude, cirrus was detected by the lidar. By volume, we found that $85 \%$ of the ISSRs $\left(\mathrm{RH}_{\mathrm{I}}>100 \%\right)$ contained clouds. There are only very few cases (15\% vol.) of particle-free ISSRs. Errors to this assessment arise primarily by temporal and local differences between the lidar and the radiosonde which are difficult to asses since changes in the vertical profiles occur in an unpredictable way. However, it is reasonable to conclude that within the error limits our observations suggest that ISSRs generally contain ice particles.

Figure 4 shows the PDF of $\mathrm{RH}_{\mathrm{I}}$ inside clouds which is typically around $100 \%$ in good agreement with in situ observations (Ovarlez et al., 2002). Supersaturations higher than $130 \%$ are relatively rare. The thickest clouds are observed at 


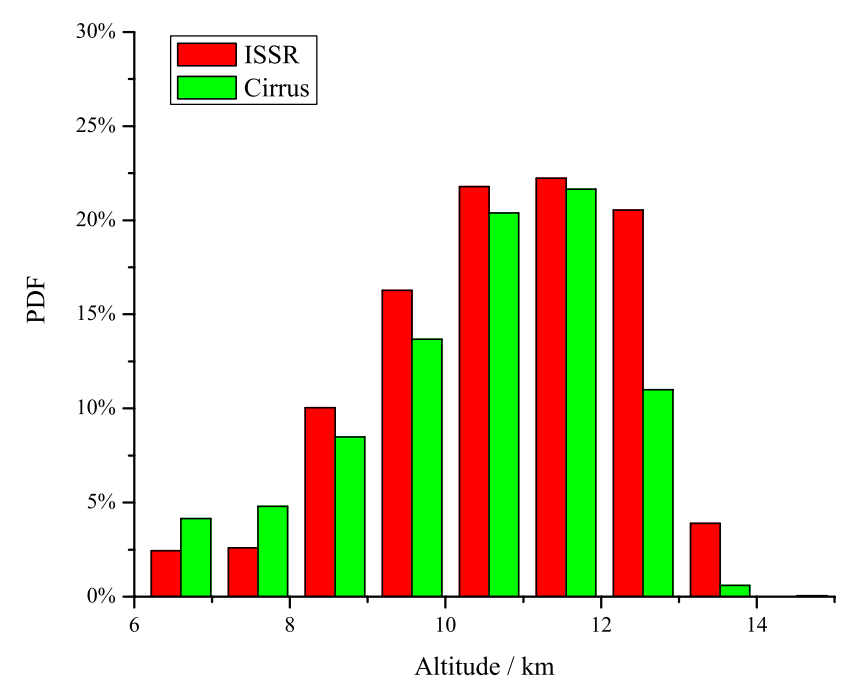

Fig. 3. Altitude distributions of ISSRs based on radiosonde observations (red) and cirrus based on lidar observations (green).

$\mathrm{RH}_{\mathrm{I}}$ between $100 \%$ and $120 \%$ and with backscatter ratios of 10 in average. We could not detect a strong relation between $\mathrm{RH}_{\mathrm{I}}$ and the optical depth of cirrus. At higher supersaturations $\mathrm{RH}_{\mathrm{I}}>130 \%$ however, clouds tend to be optically very thin suggesting that cirrus are just about to form and have not yet depleted the water vapour in the gas phase.

The probability of encountering ISSRs is highest at 11$12 \mathrm{~km}$ altitude (Fig. 3, the major cruising altitude of aircrafts, where by volume we found taht $50 \%$ of the air was supersaturated. This number dropped to $5 \%$ at $8 \mathrm{~km}$. On the other hand at these lower altitudes the ISSRs are always cloudy while the probability of finding particle-free ISSR is largest near the tropopause at $13 \mathrm{~km}$ altitude where "only" $80 \%$ vol. of supersaturated air was found to be cloudy. This is also demonstrated in Fig. 3 which shows that ISSRs extend frequently into tropopause region around $13 \mathrm{~km}$ while cirrus tend to stay below this altitude range.

\subsection{Cirrus types and contrails}

While the lidar measures the altitude and the optical depths of clouds with high precision it is difficult to assess the cloud types from the lidar observations alone. Therefore, we used images from the sky taken by a video camera (Sony DFVV300) to identy cloud types. Figure 5 shows in its upper panel pictures from that camera that were stored automatically along with each lidar profile on day time. These images show a clear sky with some persistent contrails and cirrus clouds passing by occasionally. Contrails are observed every 10 to $15 \mathrm{~min}$ at the zenith as a consequence of heavy air traffic in the southeast of Berlin. The lidar probes a small spot in about the centre of the camera pictures. The backscatter signals reveal that cirrus is always present during the entire time

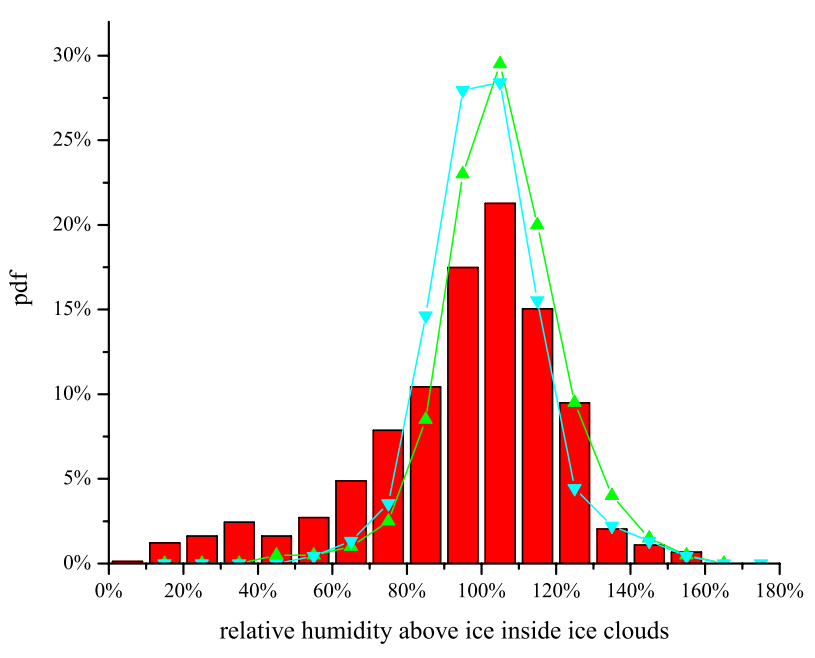

Fig. 4. PDF of the relative humidity above ice measured by radiosondes in the altitude ranges where the lidar detected cirrus clouds. For comparison, in situ measurements from the INCA campaigns (Northern Hemisphere: green, Southern Hemisphere: cyan) are shown (Ovarlez et al., 2002).

even in those moments when the pictures show no evidence for the presence of contrails or clouds. The contrails are embedded in a partly subvisible cirrostratus. This is a typical situation for a clear summer day of 2003 and was observed on all the days marked with an arrow in Fig. 2.

Figure 6 regroups the cirrus that were observed by the lidar in Lindenberg into the different types mentioned earlier based on the images that were taken by the digital camera. Most of the ice clouds were thin Cirrostrati followed by subvisible cirrus clouds which account for about one third of the total cirrus amount. As shown in Fig. 2 persistent contrails were observed frequently during days with high cirrus coverage. The simultaneous inspection of the camera pictures and the lidar data revealed that the majority of these contrails are embedded into pre-existing cirrus. Contrails that are not embedded in cirrus were either short lived or occurred shortly before stratiform cirrus was detected. Such a case was observed on 15.09.2003 where some persistent contrails occurred in cloud free air during about $1 \mathrm{~h}$ before a thick cirrostratus moved in which was generated by a warm conveyor belt. In its leading edge moist air provided the conditions for persistent contrails but cirrus clouds have not yet formed.

Since contrails are mostly embedded in pre-existing cirrostratus, it is difficult to identify the contrails from lidar backscatter profiles. Contrails show somewhat stronger backscatter and sometimes seem to have different depolarisation behaviour than the "natural" clouds, however, we did not find any unambiguous way to identify contrails based on the lidar data alone. One reason for this is that the averaging time of the lidar is $140 \mathrm{~s}$ while it takes only some seconds for the contrail to pass over through the laser beam. Therefore, 


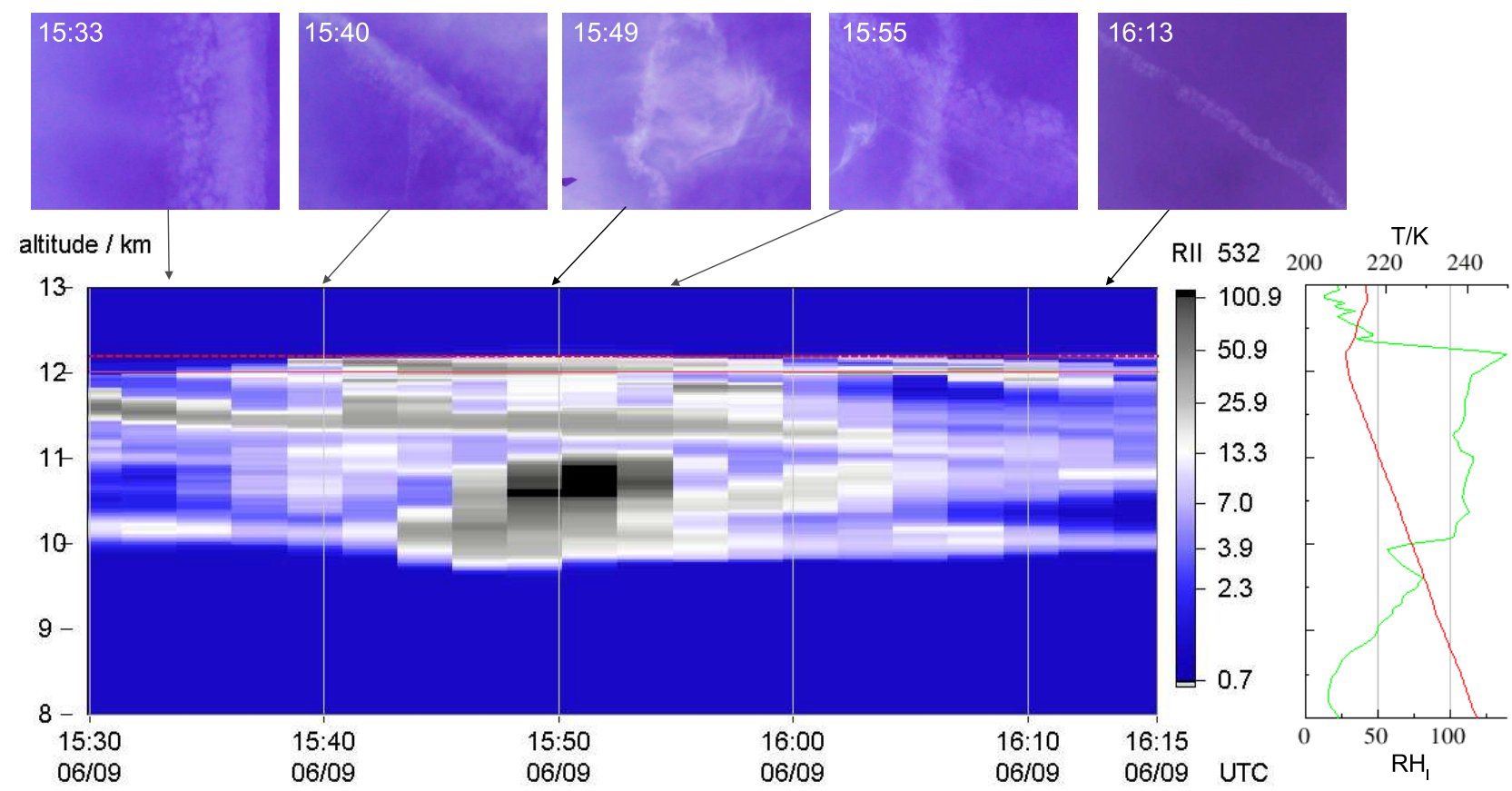

Fig. 5. The upper panel contains images from a video camera taken from the zenith above the lidar system which was located at Lindenberg. The lower panel shows a time-altitude section of the lidar backscatter ratio. The contrails that are observed by the camera are embedded in a cirrus that covers the altitude range from $10 \mathrm{~km}$ to the tropopause (red dashed line) at $12.2 \mathrm{~km}$. The most prominent cloud at about 15:50 UT is a cirrus spissatus which is also clearly visible in the lidar data. The plot on the right side shows $T$ (red) and $\mathrm{RH}_{\mathrm{I}}$ (green) measured by a radiosonde launched at 16:45 UT.

the effect of the contrail is smoothed out in the lidar data. The changes induced by the airplanes to the optical properties of the cirrus are rather subtle from the "lidar perspective" even though it is clearly evident for the bare eye.

The combination of lidar and sky camera allowed us to demonstrate, that the majority of stable contrail are embedded in pre-existing, mostly subvisible cirrus clouds. This finding is not surprising given the result of the previous section, where we demonstrated that ice particles are generally present in ISSRs. The plot on the right hand side of Fig. 5 shows the $\mathrm{RH}_{\mathrm{I}}$, in the altitude range where $\mathrm{RH}_{\mathrm{I}}>100 \%$ subvisible cirrus and contrails are observed. Supposing that both require not more and not less than supersaturation with respect to ice in order to persist, its obvious that both are regularly observed simultaneously. As a consequence, one should think of contrails as a rearrangement of an existing cloud rather than a creation of a new, artificial cloud.

\subsection{Comparison with the cloud prognostic variables of opECMWF}

Figure 7 shows a comparison of lidar observations of cirrus clouds with the IWC represented by opECMWF. The agreement is amazingly good, the ECMWF model captures the cloud events in its temporal and vertical extend as well as in

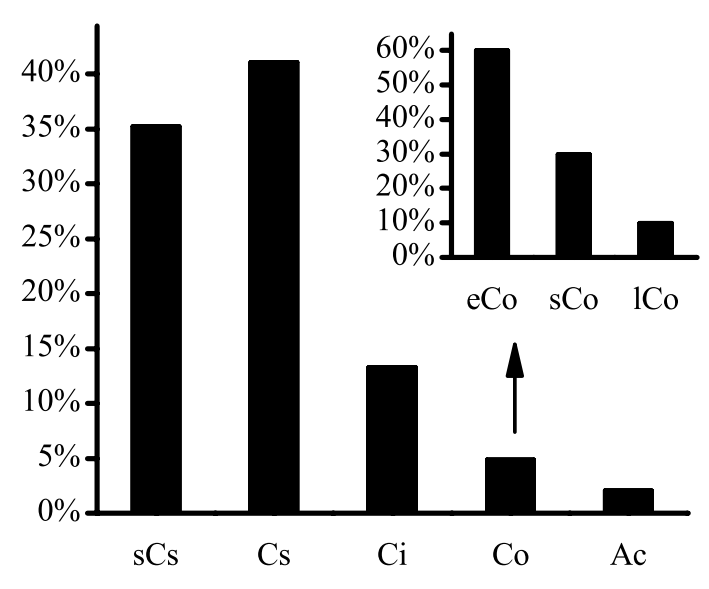

Fig. 6. Classification of cirrus clouds observed during August and September 2003 at Lindenberg by lidar and CCD Camera. Cs: Cirrostratus, Ci: Cirrus, Co: contrails, sCs: subvisible ice cloud, $1 \mathrm{Co}$ : line shaped contrails, sCo: spreaded contrail, eCo: contrails embedded in pre-existing cirrostratus.

its strengths. This agreement is striking since the model was not expected to reproduce cirrus clouds properly. An earlier attempt to compare ECMWF with lidar observation based 


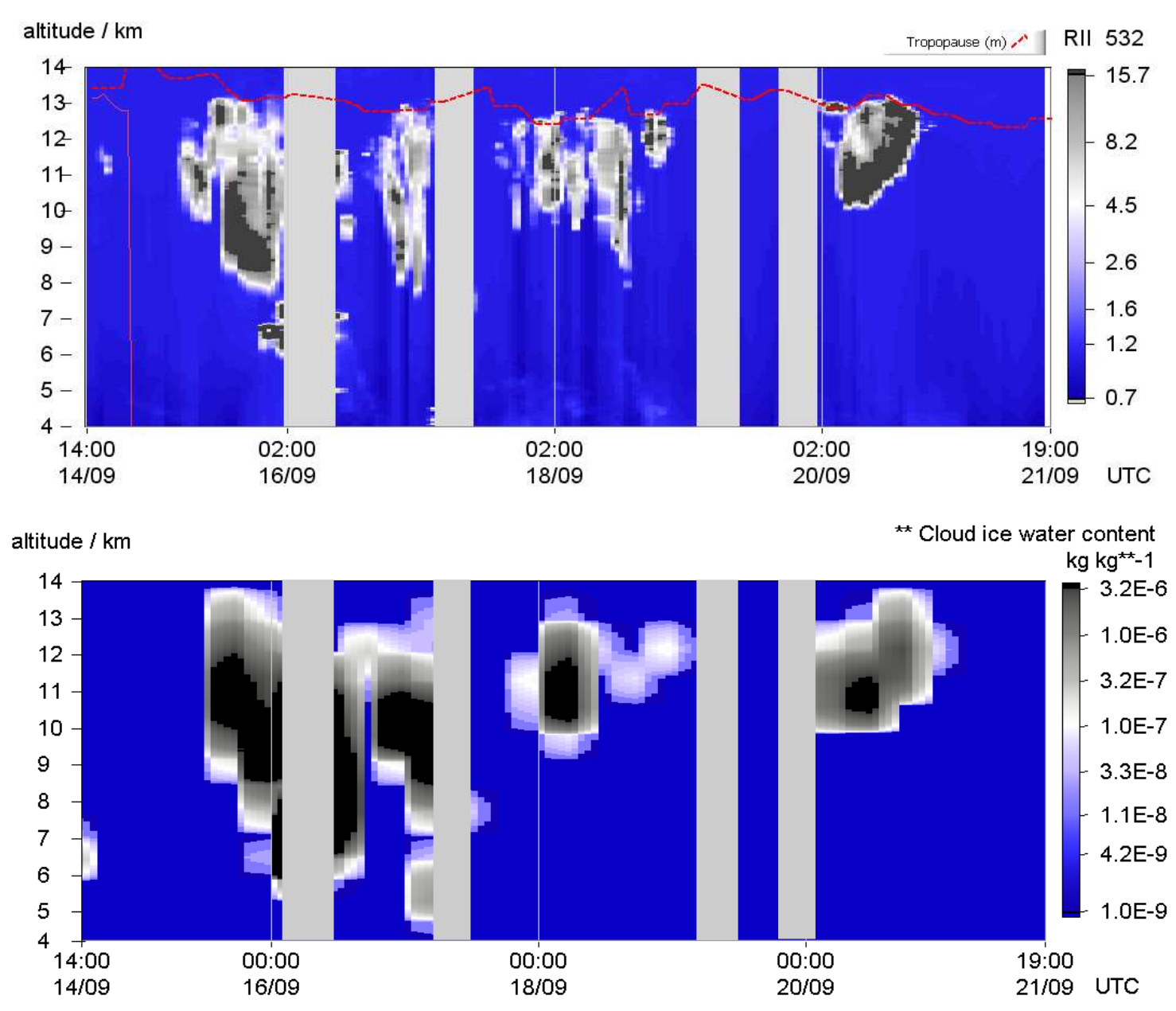

Fig. 7. The upper plot shows lidar observations of cirrus clouds in term of the backscatter ratio at $532 \mathrm{~nm}$ for one week in September 2003. The lower plot shows the corresponding cloud ice water content of opECMWF for the same time period at the nearest gridpoint to Lindenberg $\left(52^{\circ}, 14^{\circ}\right)$. Periods where no lidar data was available are painted in grey.

on the data from campaigns in 2000 (Immler and Schrems, 2002) was less clear. The reasons why the cirrus observed at Lindenberg compare much better may be the following: First, at Lindenberg we were sampling mainly anticyclonic cirrus while during previous campaigns the focus was on cirrus formed in frontal system or in orographic waves (Gayet et al., 2006). Presumably, the model reproduces the anticyclonic cloud formation better than the more complicated, dynamical processes in fronts and small scale waves. Secondly, the cloud formation scheme and the assimilation of humidity observations in opECMWF have changed between 2000 and 2003 and the newer schemes seems to perform better as far as their effects on the occurrence of mid-latitude cirrus is concerned.

Starting from 2004 we conducted a number of campaigns in the tropics. Thin ice clouds in the tropical tropopause region were extensively studied with the same lidar instrument. Again, we found a close relation between cloud observations and the output of the ECMWF model suggesting that stratiform clouds in general are well captured by the models prognostic clouds scheme (Immler et al., 2007). The good agreement between the observation of stratiform cirrus and its prediction in the ECMWF model supports our conclusion that ice particles are present in air that is saturated with respect to ice, independently from the radiosonde data. Since upper air radiosonde observation are not assimilated to the analysis, the humidity of upper tropospheric air and consequently the occurrence of clouds in the model are consequences of vertical transport and cooling of air masses. As we have pointed out in Sect. 2.3 stratiform clouds are formed by the model when saturation is reached. The agreement between model and observations demonstrates that this rather simple concept works well in the conditions that were investigated here.

Differences between the observations and the model data occur mainly because of a temporal delay between the two datasets: clouds in the opECMWF often occur one time step 
later than they were actually observed. Also the vertical extent sometimes differs by one or two model levels. The first can easily be corrected for and the latter can be ignored if vertically integrated parameters are compared. This is done in Fig. 8 where the cloud OD measured by the lidar, averaged to the model scales, are plotted against the integrated ice water content (= Ice water path, IWP) of opECMWF on a double logarithmic scale. The correlation coefficient of 0.93 demonstrates that model and observations agree very well. We did not find a systematic difference between clouds observed during cyclonic (blue) and high pressure (red) weather systems. Figure 8 provides an empiric relation between the (prognostic) variable IWP (which can be easily translated to an IWC when considering a specific layer) and the optical depth of stratiform cirrus clouds that can be very useful for modelling the radiative properties of these cloud types.

Moreover, it allows an estimation of the typical effective particle size. IWP and OD scale linearly with the total particle number in a column $\left(N_{t}\right)$. On the other hand, OD scales with the square of the effective particle radius $r$ while IWP scales with $r^{3}$. The slope of about 0.6 of the regression indicates that an increase of the OD of stratiform cirrus is primarily due to an increase in effective particle size $(r)$ rather than particle number $\left(N_{t}\right)$. If a change in number is dominant, a slope close to unity is expected, while a smoother slope of $\frac{2}{3}$ was expected when $N$ is assumed constant while IWP and OD varies with $r$.

Based on this consideration, a rough estimate of the effective particle radius is obtained by assuming spherical particles with a size that is large compared to the wavelengths of the light. In this case OD is to a good approximation obtained by:

$$
\mathrm{OD}=2 N_{t} \pi r^{2}
$$

and the ice water path by

$$
\mathrm{IWP}=\frac{4}{3} N_{t} \pi r^{3} \rho
$$

where $\rho$ is the density of ice. Solving these equations for $r$ yields:

$$
r=\frac{3}{2} \frac{1}{\rho} \frac{\mathrm{IWP}}{\mathrm{OD}}
$$

While the particles of subvisible clouds ( $\mathrm{OD}=0.02$, IWP $=0.1 \mathrm{~g} / \mathrm{m}^{2}$, Fig. 8) have effective radii of about $10 \mu \mathrm{m}$, the optical properties of thick cirrus clouds $(\mathrm{OD}=0.02$, IWP $=100 \mathrm{~g} / \mathrm{m}^{2}$ ) are dominated by much larger ice crystals with typical sizes of more than $100 \mu \mathrm{m}$. Assuming a typical cloud with a thickness of $2 \mathrm{~km}$, one can conclude that the number density of the optically active particles (i.e. the particles that are responsible for the majority of the scattering) of stratiform cirrus is on the order of 10 particles per litre, independently of the clouds optical depth.

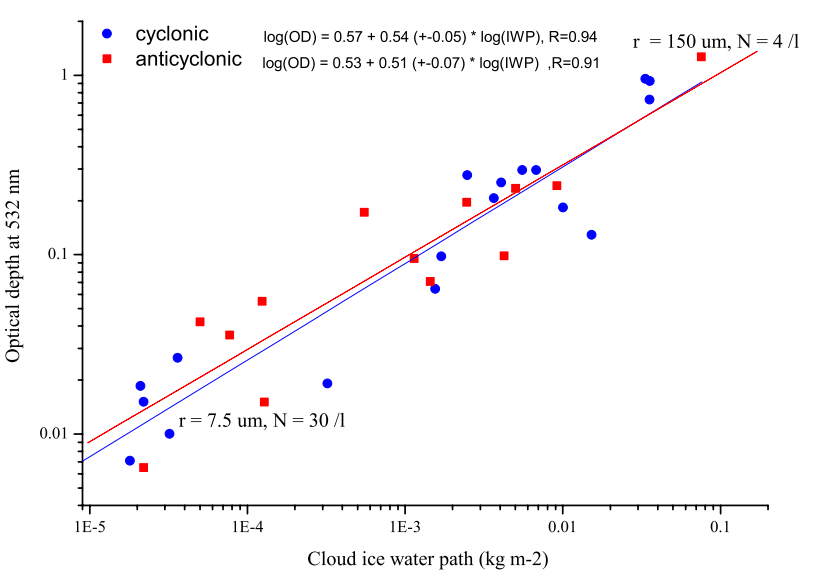

Fig. 8. Comparison of the observed total cirrus cloud optical depth determined from lidar observations with the Ice Water Path of the nearest grid-point of the opECMWF data for August and September 2003.

\section{Conclusions}

We studied the formation of thin cirrus and contrail at a midlatitude location $\left(53^{\circ} \mathrm{N}\right)$ on the basis of lidar and radiosonde observations as well as opECMWF data. Cirrus clouds were found to ubiquitous in particular in high pressure systems where the coverage with cirrus was on average $67 \%$. Ice supersaturated regions occur very often in the uppermost troposphere ( $8 \mathrm{~km}$ to tropopause) in particular within anticyclonic weather patterns and are generally cloudy: by volume, $85 \%$ of the observed ISSRs contained ice particles. The almost even PDF of optical depths of cirrus across several orders of magnitude indicate an exponential decay of cirrus, suggesting that sedimentation is the most important process for their dissipation.

The occurrence of cirrus and ISSR are closely related and our observations clearly demonstrate that cirrus and contrails are generally present where the upper troposphere is supersaturated with respect to ice. The majority of persistent contrails were embedded within pre-existing cirrus. This is an important result for assessing the impact of aircraft exhaust on climate.

The occurrence of stratiform clouds in the upper troposphere is well reproduced by the ECMWF prognostic cloud scheme. Radiosonde humidity measurements, lidar observations of ice clouds and prognostic model output thus provide a consistent picture of the occurrence of stratiform cirrus clouds at mid-latitudes. The correlation between observed total OD of ice clouds and modeled ice water path indicates that changes in the optical depth of a thin cirrus is primarily linked to the particle size. Stratiform cirrus clouds seem to be composed of a relatively small number ( 10 particles per litre) of large particles with effective radii on the order of 
$10 \mu \mathrm{m}$ for subvisible clouds and over $100 \mu \mathrm{m}$ for thick cirrus with OD around 1. Our results contrast the large amount of small particles that were found in cirrus clouds formed by strong dynamical forcing like jet streams or orographic waves (Gayet et al., 2006).

The relation between OD and IWP found in our study can be helpful for parametrising the optical properties of cirrus clouds in models. However, we do not know whether our findings are a typical feature only for the particular location of this study, or whether they can be applied to stratiform cirrus in the upper troposphere in general. It would be interesting to know whether the same results are obtained in regions with less sources of pollution, in particular with less air traffic, for answering the question whether air pollution contributes to the high cirrus frequency that we have observed at Lindenberg.

In analogy to the results reported here, observations obtained during a campaign in the tropics (Immler et al., 2007) showed that cirrus clouds were generally present in supersaturated air in an altitude of $15-18 \mathrm{~km}$, clearly above the flight levels of airplanes. This suggests that aircraft emissions do not play a major role for the existence of thin cirrus cloud layers. On the other hand, the impact of aircraft emissions on the optical properties of clouds is often clearly observable at mid-latitudes by bare eye in the form of visible contrails. The effects of anthropogenic emissions on the formation and properties of ice particles in the upper troposphere are still not readily understood to date and will be subject to further studies. Continuous, long term lidar observations and simultaneous high quality water vapour soundings deliver valuable information in this context and should play an integral role in such efforts.

Acknowledgements. We like to thank I. Beninga and W. Ruhe (impres $\mathrm{GmbH}$ ) for maintaining the MARL instrument and performing measurements. Also, we thank the staff at Lindenberg for their support. Thanks to the ECMWF for giving access to their database. This study was financially supported by the "Strategiefondsprojekt" PAZI of the Helmholtz foundation.

Edited by: R. Vautard

\section{References}

Abbatt, J. P. D., Benz, S., Cziczo, D. J., Kanji, Z., Lohmann, U., and Möhler, O.: Solid Ammonium Sulfate Aerosols as Ice Nuclei: Pathway for Cirrus Cloud Formation, Science, 313, 1770-1773, doi:10.1126/science.1129726, 2006.

Ansmann, A., Wandinger, U., Riesbel, M., Weitkamp, C., and Michaelis, W.: Independent measurement of extinction and backscatter profiles in cirrus clouds by using a combined Raman elastic-backscatter lidar, Appl. Optics, 31, 7113-7131, 1992.

Cziczo, D. J., Murphy, D. M., Hudson, P. K., and Thomson, D. S.: Single particle measurements of the chemical composition of cirrus ice residue during CRYSTAL-FACE, J. Geophys. Res., 109, D04201, doi:10.1029/2003JD004032, 2004.
Dessler, A. E., Palm, S. P., Hart, W. D., and Spinhirne, J. D.: Tropopause-level thin cirrus coverage revealed by ICESat/Geoscience Laser Altimeter System, J. Geophys. Res., 111, D08203, doi:10.1029/2005JD006586, 2006.

Gayet, J.-F., Ovarlez, J., Shcherbakov, V., Ström, J., Schumann, U., Minikin, A., Auriol, F., Petzold, A., and Monier, M.: Cirrus cloud microphysical and optical properties at southern and northern midlatitudes during the INCA experiment, J. Geophys. Res., 109, D20206, doi:10.1029/2004JD004803., 2004.

Gayet, J. F., Shcherbakov, V., Mannstein, H., Minikin, A., Schumann, U., Ström, J., Petzold, A., Ovarlez, J., and Immler, F.: Microphysical and optical properties of mid-latitude cirrus clouds observed in the southern hemisphere during INCA, , Q. J. Roy. Meteor. Soc., 132, 2791-2748, doi:10.1256/qj.05.162, 2006.

Gierens, K., Schumann, U., Helten, M., Smit, H., and Marenco, A.: A distribution law for relative humidity in the upper troposphere and lower stratosphere derived from three years of MOZAIC measurements, Ann. Geophys., 17, 1218-1226, 1999, http://www.ann-geophys.net/17/1218/1999/.

Goldfarb, L., Keckhut, P., Chanin, M.-L., and Hauchecorne, A.: Cirrus Climatological Results from Lidar Measurements at OHP (44ํ N, $\left.6^{\circ} \mathrm{E}\right)$, Geophys. Res. Lett., 28, 1687-1690, 2001.

Heymsfield, A. J., Miloshevich, L. M., Twohy, C., Sachse, G., and Oltmans, S.: Upper tropospheric relative humidity observations and implications for cirrus ice nucleation, Geophys. Res. Lett., 25, 1343-1346, 1998.

Heymsfield, A. J., Schmitt, C. G., Bansemer, A., Baumgardner, D., Weinstock, E. M., Smith, J. T., and Sayres, D.: Effective ice particle densities for cold anvil cirrus, Geophys. Res. Lett., 31, L02101, doi:10.1029/2003GL018311, 2004.

Hogan, R., Jakob, C., and Illingworth, A.: Comparison of ECMWF winter-season cloud fraction with radar-derived values, J. Appl. Meteorol., 40, 513-525, 2001.

Immler, F. and Schrems, O.: Lidar measurements of cirrus clouds in the northern and southern hemisphere during INCA $\left(55^{\circ} \mathrm{N}\right.$, $53^{\circ} \mathrm{S}$ ): A comparative study, Geophys. Res. Lett., 29, 1809, doi: 10.1029/2002GL015077, 2002.

Immler, F., Krüger, K., Tegtmeier, S., Fujiwara, M., Fortuin, P., Verver, G., and Schrems, O.: Cirrus clouds, humidity, and dehydration in the tropical tropopause layer observed at Paramaribo, Suriname $\left(5.8^{\circ} \mathrm{N}, 55.2^{\circ} \mathrm{W}\right)$, J. Geophys. Res., 112, D03209, doi: 10.1029/2006JD007440, 2007.

Jensen, E., Toon, O., Vay, S., Ovarlez, J., May, R., Bui, T., Twohy, C., Gandrud, B., Pueschel, R., and Schumann, U.: Prevalence of ice-supersaturated regions in the upper troposphere: Implications for optically thin ice cloud formation, J. Geophys. Res., 106, 17 253-17 266, 2001.

Kärcher, B.: Properties of subvisible cirrus clouds formed by homogeneous freezing, Atmos. Chem. Phys., 2, 161-170, 2002, http://www.atmos-chem-phys.net/2/161/2002/.

Kley, D., Russell III, J., and Phillips, C.: Assessment of upper tropospheric and stratospheric water vapour, Tech. Rep. 1043, SPARC/WMO, 2000.

Leiterer, U., Dier, H., and Naebert, T.: Improvements in Radiosonde Humidity Profiles using RS80/RS90 Radiosondes of Vaisala, Beiträge zur Physik der Atmosphäre, 70, 4, 319-336, 1997.

Li, J.-L., Waliser, D. E., Jiang, J. H., Wu, D. L., Read, W., Waters, J. W., Tompkins, A. M., Donner, L. J., Chern, J.-D., Tao, W.-K., Atlas, R., Gu, Y., Liou, K. N., Genio, A. D., Khairoutdi- 
nov, M., and Gettelman, A.: Comparisons of EOS MLS cloud ice measurements with ECMWF analyses and GCM simulations: Initial results, Geophys. Res. Lett., 32, L18710, doi: 10.1029/2005GL023788, 2005.

Liou, K.-N.: Influence of Cirrus Clouds on Weather and Climate Processes: A Global Perspective, Mon. Weather Rev., 114, 6, 1167-1199, 1986.

Meerkötter, R., Schumann, U., Doelling, D. R., Minnis, P., Nakajima, T., and Tsushima, Y.: Radiative forcing by contrails, Ann. Geophys., 17, 1080-1094, 1999, http://www.ann-geophys.net/17/1080/1999/.

Miller, S., Stephens, G., and Beljaars, A.: A validation survey of the ECMWF prognostic cloud scheme using LITE, Geophys. Res. Lett., 26, 1417-1420, 1999.

Miloshevich, L. M., Vömel, H., Paukkunen, A., Heymsfield, A., and Oltmans, S.: Characterization and Correction of Relative Humidity Measurements from Vaisala RS80-A Radiosondes at Cold Temperatures, J. Atmos. Oceanic Techn., 18, 135-156, 2001.

Miloshevich, L. M., Vömel, H., Whiteman, D. N., Lesht, B. M., Schmidlin, F. J., and Russo, F.: Absolute accuracy of water vapor measurements from six operational radiosonde types launched during AWEX-G and implications for AIRS validation, J. Geophys. Res., 111, D09S10, doi:10.1029/2005JD006083, 2006.

Ovarlez, J., Gayet, J.-F., Gierens, K., Ström, J., Ovarlez, H., Auriol, F., Busen, R., and Schumann, U.: Water Vapour Measurements inside cirrus clouds in Northern and Southern hemispheres during INCA, Geophys. Res. Lett., 29, 1813, doi:10. 1029/2001GL014440, 2002.

Palm, S., Benedetti, A., and Spinhirne, J.: Validation of ECMWF global forecast model parameters using GLAS atmospheric channel measurements, Geophys. Res. Lett., 32, L22S09, doi: 10.1029/2005GL023535, 2006.

Penner, J., Lister, D., Griggs, D., Dokken, D., and McFarland, M. (Eds.): Aviation and the Global Atmosphere, IPCC special report, Cambridge University Press, UK, 1999.

Sassen, K. and Campbell, J.: A midlatitude cirrus cloud climatology from the facility for atmospheric remote sensing. Part I: Macrophysical and synoptic properties, J. Atmos. Sci., 58, 481-496, 2001.
Sassen, K., Griffin, M., and Dodd, G.: Optical scattering and microphysical properties of subvisual cirrus clouds, and climatic implications, J. Appl. Meteor., 28, 91-98, 1989.

Schäfer, H.-J., Schrems, O., Beyerle, G., Hofer, B., Mildner, W., and Theopold, F.: Shipborne measurements with a modular multi-purpose mobile lidar system for tropospheric and stratospheric aerosol observations, SPIE EurOpto Series, 3104, 265273, 1997.

Sonntag, D.: Advances in the field of hygrometry, Meteorologische Zeitschrift, 3, 51-66, 1994.

Spichtinger, P., Gierens, K., Leiterer, U., and Dier, H.: Ice superaturation in the tropopause region over Lindenberg, Germany, Meteorologische Zeitschrift, 12, 3, 143-156, 2003.

Spichtinger, P., Gierens, K., and Lohmann, U.: Importance of a proper treatment of ice crystal sedimentation for cirrus clouds in large-scale models, in: AMS Cloud Physics Conference Proceedings, P1.60, available at: http://ams.confex.com/ams/ pdfpapers/112924.pdf, 2006.

Ström, J., Seifert, M., Kärcher, B., Ovarlez, J., Minikin, A., Gayet, J.-F., Krejci, R., Petzold, A., Auriol, F., Haag, W., Busen, R., Schumann, U., and Hansson, H. C.: Cirrus cloud occurrence as function of ambient relative humidity: a comparison of observations obtained during the INCA experiment, Atmos. Chem. Phys., 3, 1807-1816, 2003, http://www.atmos-chem-phys.net/3/1807/2003/.

Tiedtke, M.: Representation of clouds in large-scale models, Mon. Weather Rev., 121, 3040-3061, 1993.

Toon, O. and Miake-Lye, R.: Subsonic Aircraft: Contrail and Cloud Effects Special Study (SUCCESS), Geophys. Res. Lett., 25, 1109, doi:10.1029/98GL00839, 1998.

Treffeisen, R., Krejci, R., Ström, J., Engvall, A., Herber, A., and Thomason, L.: Humidity observations in the Arctic troposphere over Ny-Ålesund, Svalbard based on 15 years of radiosonde data, Atmos. Chem. Phys., 7, 2721-2732, 2007, http://www.atmos-chem-phys.net/7/2721/2007/.

Solomon, S., Qin, D., Manning, M., Marquis, M., Averyt, K., Tignor, M. M. B., Miller Jr., H. L., and Chen, Z. (Eds.): Climate Change 2007, The Physical Science Basis, Cambridge University press, 2007. 